\title{
Exigência de Arginina Digestível para Frangos de Corte Machos em Diferentes Fases ${ }^{1}$ Anel Atencio², Luiz Fernando Teixeira Albino ${ }^{3}$, Horacio Santiago Rostagno ${ }^{3}$, Débora Cristine de Oliveira Carvalho4, Flávio Medeiros Vieites ${ }^{2}$, Júlio Maria Ribeiro $\mathrm{Pupa}^{2}$
}

\begin{abstract}
RESUMO - Três ensaios foram realizados com o objetivo de determinar a exigência de arginina digestível e a relação arginina:lisina digestível para frangos, machos, Avian Farm nas fases de 1 a 20, de 24 a 38 e de 44 a 56 dias de idade. Os experimentos foram conduzidos em delineamento inteiramente casualizado com cinco níveis de arginina digestível, seis repetições e 20 aves por boxe nas fases de 1 a 20 e de 24 a 38 dias de idade e 16 aves por boxe na fase de 44 a 56 dias de idade. Os níveis de arginina digestível utilizados nas diferentes fases foram: de 1 a 20 dias de idade, 1,10 a 1,34\% (aumento de 0,061 entre tratamentos); de 24 a 38 dias de idade, 1,083 a 1,296\% (aumento de 0,053 ); e de 44 a 56 dias de idade, 0,96 a 1,148\% (aumento de 0,047). No final de cada experimento foram avaliadas as características de desempenho e o rendimento de carcaça. Houve efeito quadrático para ganho de peso e conversão alimentar na fase de 1 a 20 dias de idade. O valor da exigência nutricional de arginina digestível (total), estimado na fase de 1 a 20 dias de idade, foi de 1,22\% (1,31\% total), correspondendo a uma relação arginina:lisina digestível de 105\%, de acordo com os resultados de ganho de peso e o modelo descontínuo. Não houve efeito dos níveis de arginina sobre as características de desempenho e de cortes nobres, sugerindo que o nível de arginina digestível de 1,083 (1,155\% total), correspondente a uma relação de $102 \%$, foi suficiente para maximizar o desempenho na fase de 24 a 38 dias. No período de 44 a 56 dias, não houve efeito dos níveis de arginina digestível sobre as características de desempenho e de cortes nobres, indicando que o nível de treonina digestível de $0,960 \%$ (1,026\% total), correspondente a uma relação de $102 \%$, foi suficiente para maximizar o desempenho.
\end{abstract}

Palavras-chave: aminoácidos, arginina, exigências, frangos de corte

\section{Arginine Requirement of Male Broiler Chicks in Different Phases of Development}

\begin{abstract}
Three experiments were conducted to determine the arginine requirement and the digestible arginine:lysine ratio of broiler males, from 1 to 20, 24 to 38 and 44 to 56 days of age. A completely randomized design with five levels of arginine, six replicates and 20 birds per pens from 1 to 20 and 24 to 38 , and 16 birds per pens from 44 to 56 were used in each experiment. The concentrations of digestible arginine were 1.10-1.34 (increase of 0,061), 1.083-1.296 (increase of 0,053) and 0,96-1,148\% (increase of 0,047) for 120, 24-38 and 44-56 days of age respectively. At the end of each experiment performance and carcass yield were evaluated. Body weight gain and feed conversion responded quadratically to increasing levels of digestible arginine in the first phase. Using the broken line model, the requirement of digestible arginine and the ratio of digestible arginine:lysine for the first phase were $1,22 \%(1,31 \%$ total) and $105 \%$, respectively, according to the results of body weight gain. No statistical difference in the second and third phases (24-38 days old and 44-56 days old, respectively) showed that the lowest level of digestible arginine of $1,083 \%(1,155 \%$ total $)$ and $0,960 \%(1,026)$ met the birds requirement. These levels corresponded to a ratio of $102 \%$ in both phases.
\end{abstract}

Key Words: amino acid, arginine, broilers, requirement

\section{Introdução}

No passado, as dietas para aves eram formuladas com base na proteína bruta, o que podia resultar em grandes perdas energéticas e econômicas, principalmente quando ocorriam desbalanços na relação dos aminoácidos. $\mathrm{O}$ excesso de proteína ou desbalanço entre os aminoácidos (essenciais e não-essenciais) é catabolizado e excretado na forma de ácido úrico. O custo metabólico para incorporar um aminoácido em uma cadeia protéica é de $4 \mathrm{~mol}$ de ATP e para eliminá-lo, de 6 mol de ATP/g de N (Mc Leod, 1997).

Atualmente, recomenda-se formular dietas com aminoácidos na proporção ideal, de modo que não existam deficiências ou excessos. Contudo, para uma proteína ou combinação de proteína ser considerada ideal, todos os 20 aminoácidos devem estar presentes

\footnotetext{
${ }^{1}$ Parte da tese de Doutorado do primeiro autor à UFV

2 Doutor em Zootecnia (anel@uga.edu).

3 Professor do DZO/UFV.

${ }^{4}$ Estudante de Doutorado/UFV.
} 
na dieta em níveis exatos, para máxima deposição de proteína e mantença (Parsons \& Baker,1994).

Vários estudos têm sido realizados com o objetivo de determinar as exigências de arginina, quinto aminoácido limitante nas dietas com milho e farelo de soja para frangos de corte após metionina + cistina, lisina, treonina e triptofano. Burton \& Waldroup (1997) encontraram exigência de arginina total de 1,40\% em frangos de corte de 1 a 28 dias de idade, recebendo dieta com $21 \%$ de proteína bruta. Costa et al. (2001), utilizando frangos de corte machos Ross de 22 a 42 dias de idade e sete relações arginina: lisina, variando de 95 a $132,5 \%$, não observaram efeito do nível de arginina sobre as características de desempenho, entretanto, à medida que aumentou a relação arginina:lisina, houve efeito linear crescente, para rendimento de perna, e linear decrescente, para gordura abdominal.

Mack et al. (1999) sugerem relação arginina:lisina de $112 \%$ para a fase de 20 a 40 dias, enquanto Rostagno et al. (2000) recomendam valores de exigência de arginina total de 1,37 (1,28\% digestível), 1,25 ( $1,16 \%$ digestível) e 1,10\% (1,02 digestível) para as fases de 1 a 21, 22 a 42 e 43 a 56 dias de idade, respectivamente.

De acordo com as recomendações supracitadas em relação a argina:lisina, constata-se que ainda existem controvérsias quanto às exigências de arginina. Por isso, este trabalho foi realizado com os objetivos de determinar as exigências de arginina digestível para frangos de corte machos, Avian Farm, nas diferentes fases de criação, e calcular as respectivas relações arginina:lisina digestível.

\section{Material e Métodos}

A presente pesquisa foi conduzida na Seção de Avicultura do Departamento de Zootecnia do Centro de Ciências Agrárias da Universidade Federal de Viçosa, utilizando-se frangos de corte da linhagem Aviam Farm.

Foram realizados três experimentos no período de 20/05/2001 a 15/07/2002, em um galpão de alvenaria, com pé direito de 3,0 metros de altura, cobertura com telhas de cimento amianto provido de lanternim, mureta com laterais de $0,50 \mathrm{~m}$ e tela de $1 / 2$ ', Foram empregados boxes de $1,25 \times 1,80 \mathrm{~m}\left(2,25 \mathrm{~m}^{2}\right) \mathrm{com}$ piso de cimento, onde foi colocada maravalha como cama (altura de $10 \mathrm{~cm}$ ).

As condições ambientais foram monitoradas diariamente, cinco vezes ao dia (7, 10, 13, 16 e $19 \mathrm{~h})$, durante os diferentes períodos experimentais, por meio de termômetros de máxima e mínima, de bulbo seco e úmido e de globo negro.

Os aminoácidos sintéticos HCl-lisina (99\%), DL-metionina (99\%), L-treonina $(98,5 \%)$ e L-arginina (99\%) foram suplementados em quantidades necessárias para atender o padrão de perfil de aminoácido recomendado pela literatura. Para a suplementação dos aminoácidos sintéticos nas respectivas rações, foi considerada a digestibilidade de cada aminoácido de 97,91; 98,9; 92,4; e 95\%, respectivamente, segundo recomendações de Rostagno et al.(2000).

Carbonato de potássio foi adicionado às dietas experimentais nas diferentes fases, com o objetivo de manter o equilíbrio eletrolítico próximo do valor sugerido por Mongin (1981), de acordo com a seguinte fórmula: equilíbrio eletrolítico da dieta $=\left(\% \mathrm{Na}^{+} \mathrm{x}\right.$ $\left.100 / 22,990^{*}\right)+\left(\% \mathrm{~K}^{+} \mathrm{x} 100 / 39,102^{*}\right)-\left(\% \mathrm{Cl}^{-} \mathrm{x} 100 /\right.$ $\left.35,453^{*}\right)$. Equivalente grama do $\mathrm{Na}^{+}, \mathrm{K}^{+}$ou $\mathrm{Cl}^{-}$, respectivamente.

No primeiro experimento (1 a 20 dias de idade), utilizaram-se 600 pintos de corte, machos, com um dia de idade e peso médio de $45 \mathrm{~g}$.

$\mathrm{O}$ delineamento experimental utilizado foi o inteiramente casualizado, totalizando cinco tratamentos, com seis repetições e 20 aves por unidade experimental.

A dieta basal deficiente em arginina (Tabela 1) foi formulada segundo as recomendações de Rostagno et al. (2000), exceto para a relação dos aminoácidos metionina+cistina, treonina, triptofano, arginina e glicina. A lisina digestível foi escolhida como padrão (100\%) e o nível nas dietas experimentais foi de $1,160 \%$. O perfil de aminoácidos adotado para testar as recomendações de alguns autores, na dieta com proteína ideal foi de $71 \%$ para metionina + cistina (Rostagno et al., 2000), 67\% para treonina (Baker \& Han, 1994), 105\% para arginina (Baker \& Han, 1994), $19 \%$ para triptofano (5\% superior ao recomendado por Baker \& Han, 1994) e $170 \%$ para glicina+serina total/ lisina digestível (Schutte et al., 1997).

A dieta basal deficiente em arginina, com relação arginina:lisina digestível de $95 \%$, recebeu suplementação de L-arginina (99\%), para se obterem perfis de 100, 105 (nível recomendado por Rostagno et al., 2000), 110 e $115 \%$, correspondentes a níveis de arginina digestível de 1,$10 ; 1,218 ; 1,276 ; 1,334$; e $1,392 \%$ por $\mathrm{kg}$ da dieta e níveis de arginina total de 1,$180 ; 1,241 ; 1,302 ; 1,363$ e $1,424 \%$ por kg de dieta.

R. Bras. Zootec., v.33, n.6, p.1456-1466, 2004 
Tabela 1 - Composição percentual da ração basal para a fase de 1 a 20 dias

Table 1 - Percentage and composition of the experimental diets (1 to 20 days)

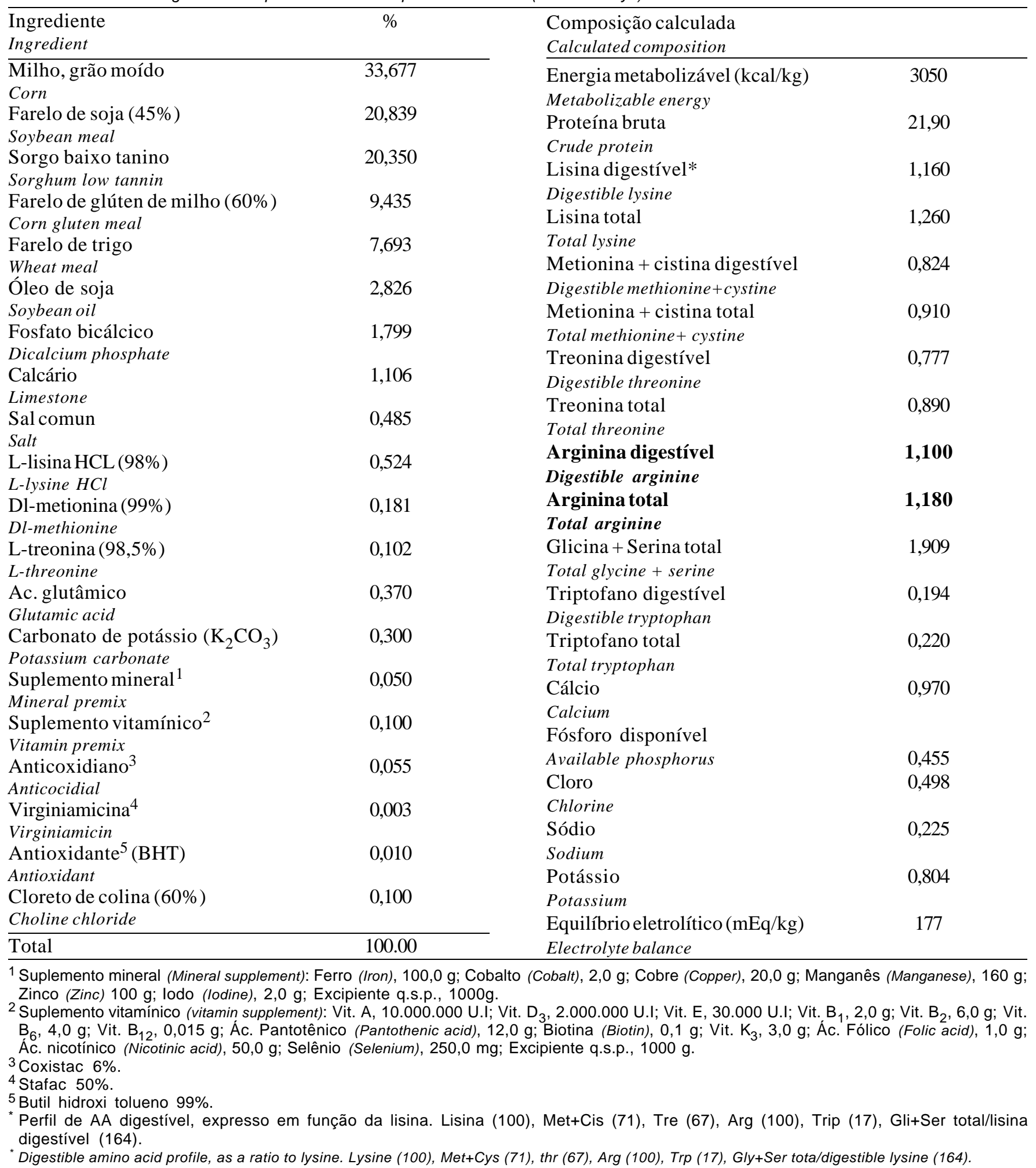


As suplementações com L-arginina foram feitas em substituição ao ácido glutâmico, mantendo as dietas isoenergéticas $(3.050 \mathrm{kcal}$ de energia metabolizável) e ligeiramente isonitrogênicas $(21,9 \%$ de proteína bruta), uma vez que a arginina fornece três vezes mais $\mathrm{N}$ que o ácido glutâmico e a substituição foi peso/peso, e não pelo aporte de $\mathrm{N}$.

As dietas basais receberam adição de carbonato de potássio, para manter o equilíbrio eletrolítico da dieta em $177 \mathrm{meq} / \mathrm{kg}$ de ração.

Nos cinco primeiros dias do experimento, foram instalados bebedouros de pressão e comedouros tipo bandeja, substituídos posteriormente por bebedouros pendulares e comedouros tubulares. As aves receberam água e ração ad libitum.

Aos 20 dias de idade, as aves e as sobras de ração de cada boxe foram pesadas para avaliação do ganho de peso, do consumo de ração e da conversão alimentar.

A umidade relativa do ar média observada durante o período experimental foi de $73 \pm 7,8 \%$; o ITGU, de $72 \pm 3$; e a temperatura, de $23^{\circ} \mathrm{C}$, sendo a média das mínimas de $19^{\circ} \mathrm{C}$ e a média das máximas de $27^{\circ} \mathrm{C}$.

No segundo experimento ( 24 a 38 dias de idade), foram utilizados 600 frangos de corte, machos, com 24 dias de idade e peso médio de 930 gramas. Durante a fase inicial (1 a 24 dias), as aves receberam ração comercial à base de milho e de farelo de soja, formulada para atender às exigências nutricionais das aves em proteína, energia, cálcio e fósforo, segundo Rostagno et al. (2000).

O delineamento experimental foi semelhante ao utilizado na fase de 1 a 20 dias de idade. A dieta basal (Tabela 2) deficiente em arginina, com relação arginina:lisina digestível de $102 \%$, foi suplementada com L-arginina (99\%), em substituição ao ácido glutâmico, para se obterem perfis de 107, 112 (nível recomendado por Mack et al., 1999), 117 e 122\%, correspondentes a níveis de arginina digestível nas dietas de 1,$083 ; 1,136 ; 1,189 ; 1,243 ;$ e $1,296 \%$ e níveis de arginina total de 1,$155 ; 1,211 ; 1,267 ; 1,323$; e $1,379 \%$, respectivamente.

As dietas experimentais foram formuladas conforme recomendações de Rostagno et al. (2000), exceto para o perfil de aminoácidos. O nível de lisina digestível em todas as dietas experimentais foi de $1,062 \%$, considerado padrão (100\%). O nível de energia das dietas foi de $3.150 \mathrm{kcal}$ de EM e $19,85 \%$ de PB. O perfil de aminoácidos utilizado foi de $75 \%$ para metionina + cistina (Mack et al., 1999), 68\% para treonina (Emmert \& Baker, 1997), 19\% triptofano (Mack et al., 1999) e 170\% Glicina+Serina total/lisina digestível.

Todas as dietas, para os diferentes tratamentos, foram isonitrogênicas e isoprotéicas. $\mathrm{O}$ equilíbrio eletrolítico foi de $168 \mathrm{mEq} / \mathrm{kg}$ de dieta. No segundo experimento, foram utilizados bebedouros pendulares e comedouros tubulares. As aves receberam água e ração ad libitum.

No final do experimento (38 dias de idade), as aves e as sobras de ração de cada boxe foram pesadas, para avaliação do consumo de ração, do ganho de peso e da conversão alimentar. No mesmo dia, duas aves, com peso médio das aves de cada boxe, foram abatidas para determinação do rendimento de carcaça e do peso absoluto dos cortes nobres (peito, filé de peito e perna). O rendimento de carcaça foi obtido de carcaças evisceradas, sem cabeça, pescoço e pés.

A umidade relativa do ar média observada durante o período (do $24^{\circ}$ ao $38^{\circ}$ dia) do experimento foi de $72 \pm 5,8 \%$; o ITGU, de $69 \pm 2$; e a temperatura, de $20,7^{\circ} \mathrm{C}$, sendo as médias das mínimas de $15,5^{\circ} \mathrm{C}$ e das máximas, de $26^{\circ} \mathrm{C}$.

No terceiro experimento (44 a 56 dias de idade), utilizaram-se 480 frangos de corte, machos, com 44 dias de idade e peso médio de 2661 gramas.

As aves nesta fase receberam duas rações: uma na fase inicial ( 1 a 24 dias de idade) e outra na fase de crescimento ( 24 a 44 dias dias de idade). Ambas as rações eram à base de milho e de farelo de soja, formuladas para atender às exigências nutricionais das aves em proteína, energia, cálcio e fósforo, segundo Rostagno et al. (2000).

O delineamento experimental foi semelhante ao dos experimentos anteriores ( 1 a 21$)$ e (24 a 38 dias de idade), contudo, nesta fase, foram utilizadas 16 aves por boxe. A dieta basal (Tabela 3) deficiente em arginina, com relação arginina:lisina de $102 \%$, foi suplementada com L-arginina (99\%), em substituição ao ácido glutâmico, para se obterem perfis de 107 , 112,117 e $122 \%$, correspondentes a níveis de arginina digestível nas dietas de 0,$960 ; 1,007 ; 1,054 ; 1,101 ; \mathrm{e}$ $1,148 \%$ e níveis de arginina total de 1,$026 ; 1,077$; 1,$128 ; 1,179$; e $1,230 \%$.

A dieta basal $(17,85 \%$ de proteína bruta e $3.200 \mathrm{kcal}$ de energia metabolizável) foi formulada de acordo com as recomendações de Rostagno et al. (2000), exceto para o perfil de aminoácidos, que foi o mesmo adotado na fase de 24 a 38 dias. O nível de

R. Bras. Zootec., v.33, n.6, p.1456-1466, 2004 
Tabela 2 - Composição percentual da dieta basal para a fase de 24 a 38 dias

Table 2 - Percentage and composition of the experimental diets (24 to 38 days)

\begin{tabular}{|c|c|c|c|}
\hline \multicolumn{2}{|l|}{$\begin{array}{l}\text { Ingrediente } \\
\text { Ingredient }\end{array}$} & \multicolumn{2}{|l|}{$\begin{array}{l}\text { Composição calculada } \\
\text { Calculated composition }\end{array}$} \\
\hline Milho, grão moído & 64,629 & Energia metabolizável (kcal/kg) & 3.150 \\
\hline $\begin{array}{l}\text { Corn } \\
\text { Farelo de soia }(45 \%)\end{array}$ & 23,430 & Metabolizable energy & \\
\hline Soybean meal & & Proteína bruta & 19,85 \\
\hline Farelo de glúten de milho (60\%) & 4,789 & Crude protein & \\
\hline Corn gluten meal & & Lisina digestível & 1,062 \\
\hline Óleo de soja & 2,505 & Digestible lysine & \\
\hline Soybean oil & & Lisina total & 1,158 \\
\hline Fosfato bicálcico & 1,655 & Total Lysine & \\
\hline $\begin{array}{l}\text { Dicalcium phosphate } \\
\text { Calcário }\end{array}$ & 0,998 & Metionina + Cistina digestível & 0,797 \\
\hline Limestone & & Digestible methionine+cystine & \\
\hline $\begin{array}{l}\text { Sal comum } \\
\text { Salt }\end{array}$ & 0,413 & $\begin{array}{l}\text { Metionina }+ \text { Cistina total } \\
\text { Total methionine }+ \text { cystine }\end{array}$ & 0,875 \\
\hline L-lisina HCL (98\%) & 0,381 & Treonina digestível & 0,722 \\
\hline L-lysine $\mathrm{HCl}$ & & Digestible treonine & \\
\hline Dl-metionina (99\%) & 0,219 & Treonina total & 0,824 \\
\hline Dl-methionine & & Total threonine & \\
\hline $\begin{array}{l}\text { L-treonina }(98,5 \%) \\
\text { L-threonine }\end{array}$ & 0,093 & Arginina digestível & 1,083 \\
\hline $\begin{array}{l}\text { L-threonthe } \\
\text { L-arginina }(99 \%)\end{array}$ & 0,023 & Digestible arginine & \\
\hline$L$-arginine & & Arginia total & 1,155 \\
\hline L-Glicina & 0,039 & Total arginine & \\
\hline L-glycine & & Glicina + Serina total & 1,806 \\
\hline L-triptofano & 0,018 & Total glycine + serine & \\
\hline L-tryptophan & & Triptofano digestível & 0,202 \\
\hline Ácido glutâmico & 0,300 & Digestible tryptophan & \\
\hline $\begin{array}{l}\text { Glutamic acid } \\
\text { Carbonato de potássio }\left(\mathrm{K}_{2} \mathrm{CO}_{3}\right)\end{array}$ & 0,190 & Triptofano total & 0,222 \\
\hline Potassium carbonate & & Total tryptophan & \\
\hline Suplemento mineral ${ }^{1}$ & 0,050 & Cálcio & 0,890 \\
\hline Mineral premix & & Calcium & \\
\hline Suplemento vitamínico ${ }^{2}$ & 0,100 & Fósforo disponível & 0,410 \\
\hline Vitamin premix & & Available phosphorus & \\
\hline Anticoxidiano ${ }^{3}$ & 0,055 & Cloro & 0,384 \\
\hline Anticocidial 4 & & Chlorine & \\
\hline $\begin{array}{l}\text { Virginiamicina }^{4} \\
\text { Virginiamicin }\end{array}$ & 0,003 & Sódio & 0,200 \\
\hline Antioxidante $^{5}(\mathrm{BHT})$ & 0,010 & Sodium & \\
\hline Antioxidant & & Potássio & 0,740 \\
\hline Cloreto de colina $(60 \%)$ & 0,100 & Potassium & \\
\hline Choline chloride & & Equilíbrio eletrolítico (mEq/kg) & 168 \\
\hline Total & 100,00 & Electrolyte balance & \\
\hline
\end{tabular}

1 Suplemento mineral (Mineral supplement): Ferro (Iron), 100,0 g; Cobalto (Cobalt), 2,0 g; Cobre (Copper), $20,0 \mathrm{~g}$; Manganês (Manganese), $160 \mathrm{~g}$; Zinco (Zinc) $100 \mathrm{~g}$; lodo (lodine), $2,0 \mathrm{~g}$; Excipiente q.s.p., 1000g.

2 Suplemento vitamínico (vitamin supplement): Vit. A, 10.000.000 U.I; Vit. $D_{3}, 2.000 .000$ U.I; Vit. E, 30.000 U.I; Vit. B , 2,0 g; Vit. B , 6,0 g; Vit. $\mathrm{B}_{6}, 4,0 \mathrm{~g}$; Vit. $\mathrm{B}_{12}, 0,015 \mathrm{~g}$; Ác. Pantotênico (Pantothenic acid), $12,0 \mathrm{~g}$; Biotina (Biotin), 0,1 g; Vit. K $3,3,0 \mathrm{~g} ;$ Ác. Fólico (Folic acid), $1,0 \mathrm{~g}$; Ác. nicotínico (Nicotinic acid), 50,0 g; Selênio (Selenium), 250,0 mg; Excipiente q.s.p., $1000 \mathrm{~g}$.

${ }^{3}$ Coxistac $6 \%$.

${ }^{4}$ Stafac $50 \%$.

5 Butil hidroxi tolueno $99 \%$.

* Perfil de AA digestível, expresso em função da lisina. Lisina (100), Met+Cis (71), Tre (67), Arg (100), Trip (17), Gli+Ser total/lisina digestível (164).

*Digestible amino acid profile, as a ratio to lysine. Lysine (100), Met+Cys (71), thr (67), Arg (100), Trp (17), Gly+Ser tota/digestible lysine (164). 
Tabela 3 - Composição percentual da dieta basal para a fase de 44 a 56 dias

Table 3 - Percentage and composition of the experimental diets (44 to 56 days)

\begin{tabular}{|c|c|c|c|}
\hline \multicolumn{2}{|l|}{$\begin{array}{l}\text { Ingrediente } \\
\text { Ingredient }\end{array}$} & \multicolumn{2}{|l|}{$\begin{array}{l}\text { Composição calculada } \\
\text { Calculated composition }\end{array}$} \\
\hline Milho, grão moído & 70,840 & Energia metabolizável (kcal/kg) & 3.200 \\
\hline $\begin{array}{l}\text { Corn } \\
\text { Earelode soia }(45 \%)\end{array}$ & 17373 & Metabolizable energy & \\
\hline $\begin{array}{l}\text { Farelo de soja }(45 \%) \\
\text { Soybean meal }\end{array}$ & $1 /, 3 / 3$ & Proteína bruta & 17,85 \\
\hline Farelo de glúten de milho $(60 \%)$ & 5,057 & Crude protein & \\
\hline Corn gluten meal & & Lisina digestível & 0,941 \\
\hline Óleo de soja & 2,141 & Digestible lysine & \\
\hline Soybean oil & & Lisina total & 1,025 \\
\hline Fosfato bicálcico & 1,472 & Total lysine & \\
\hline Dicalcium phosphate & 0027 & Metionina+cistina digestível & 0,706 \\
\hline Limestone & $0,9<1$ & Digestible methionine + cystine & \\
\hline Sal comun & 0,399 & Metionina+cistina total & 0,777 \\
\hline Salt & & Total methionine + cystine & \\
\hline L-lisina HCL (98\%) & 0,403 & Treonina digestível & 0,640 \\
\hline L-lysine $\mathrm{HCl}$ & & Digestible threonine & \\
\hline DL-metionina (99\%) & 0,168 & Treonina total & 0,733 \\
\hline Dl-methionine & 0083 & Total threonine & \\
\hline $\begin{array}{l}\text { L-treonina }(99 \%) \\
\text { L-threonine }\end{array}$ & 0,083 & Arginina digestível & $\mathbf{0 , 9 6 0}$ \\
\hline L-arginina $(99 \%)$ & 0,066 & Digestible arginine & \\
\hline$L$-arginine & & Arginina total & 1,026 \\
\hline L-glisima & 0,042 & Total arginine & \\
\hline$L$-glycine & & Glicina + serina total & 1,600 \\
\hline L-triptofano & 0,028 & Total glycine + serine & \\
\hline L-tryptophan & & Triptofano digestível & 0,179 \\
\hline Ácido glutâmico & 0,300 & Digestible tryptophan & \\
\hline $\begin{array}{l}\text { Glutamic acid } \\
\text { Carbonato de potássio }\left(\mathrm{K}_{2} \mathrm{CO}_{3}\right)\end{array}$ & 0,383 & Triptofano total & 0,198 \\
\hline Potassium carbonate & & Total tryptophan & \\
\hline Suplemento mineral $^{1}$ & 0,050 & Cálcio & 0,800 \\
\hline Mineral premix & & Calcium & \\
\hline Suplemento vitamínico ${ }^{2}$ & 0,100 & Fósforo disponível & 0,370 \\
\hline Vitamin premix & & Digestible phosphorus & \\
\hline Anticoxidiano $^{3}$ & 0,055 & Cloro & 0,380 \\
\hline $\begin{array}{l}\text { Anticoccidial } \\
\text { Viroiniamicina } 4\end{array}$ & 0003 & Chlorine & \\
\hline $\begin{array}{l}\text { Virginiamicina } \\
\text { Virginiamicin }\end{array}$ & 0,003 & Sódio & 0,192 \\
\hline Antioxidante $^{5}(\mathrm{BHT})$ & 0,010 & Sodium & \\
\hline Antioxidant & & Potássio & 0,757 \\
\hline Cloreto de colina $(60 \%)$ & 0,100 & Potassium & \\
\hline Choline chloride & & Equilíbrio eletrolítico (mEq/kg) & 170 \\
\hline Total & 100,00 & Electrolyte balance & \\
\hline
\end{tabular}

${ }^{1}$ Suplemento mineral (Mineral supplement): Ferro (Iron), 100,0 g; Cobalto (Cobalt), 2,0 g; Cobre (Copper), $20,0 \mathrm{~g}$; Manganês (Manganese), $160 \mathrm{~g}$; Zinco (Zinc) $100 \mathrm{~g}$; lodo (lodine), $2,0 \mathrm{~g}$; Excipiente q.s.p., 1000g.

2 Suplemento vitamínico (vitamin supplement): Vit. A, 10.000.000 U.I; Vit. $D_{3}, 2.000 .000$ U.I; Vit. E, 30.000 U.I; Vit. B $, 2,0$ g; Vit. B $, 6,0$ g; Vit. $\mathrm{B}_{6}, 4,0 \mathrm{~g}$; Vit. $\mathrm{B}_{12}, 0,015 \mathrm{~g}$; Ác. Pantotênico (Pantothenic acid), 12,0 g; Biotina (Biotin), 0,1 g; Vit. $\mathrm{K}_{3}, 3,0 \mathrm{~g}$; Ác. Fólico (Folic acid), 1,0 g; Ác. nicotínico (Nicotinic acid), 50,0 g; Selênio (Selenium), 250,0 mg; Excipiente q.s.p., $1000 \mathrm{~g}$.

3 Coxistac $6 \%$.

${ }^{4}$ Stafac $50 \%$.

5 Butil hidroxi tolueno $99 \%$.

*Perfil de AA digestível, expresso em função da lisina. Lisina (100), Met+Cis (71), Tre (67), Arg (100), Trip (17), Gli+Ser total/lisina digestível (164).

"Digestible amino acid profile, as a ratio to lysine. Lysine (100), Met+Cys (71), thr (67), Arg (100), Trp (17), Gly+Ser tota/digestible lysine (164). 
lisina digestível em todas as dietas experimental foi de $0,941 \%$, considerado padrão $(100 \%)$. Todas as dietas para os diferentes tratamentos eram isonitrogênicas e isoprotéicas. O equilíbrio eletrolítico foi de $170 \mathrm{mEq} / \mathrm{kg}$ de dieta. Nesta fase, foram utilizadas as mesmas metodologias e características de avaliação adotadas no período de 24 a 38 dias de idade.

A umidade relativa do ar média observada no terceiro experimento foi de $70 \pm 5 \%$; o ITGU, de $67 \pm 2$; a temperatura, de $18,7^{\circ}$, sendo as médias das mínimas de $13^{\circ} \mathrm{C}$ e das máximas, de $24,5^{\circ} \mathrm{C}$.

$\mathrm{Na}$ Tabela 4, encontra-se o resumo dos níveis calculados de proteína bruta, lisina digestível e de arginina digestível utilizados nos três ensaios.

Os resultados das características estudadas foram submetidos às análises de variância e de regressão (modelos linear, quadrático e descontínuo), para determinação das exigências.

Os modelos foram escolhidos com base na significância dos coeficientes de regressão, utilizandose o teste $\mathrm{F}$, a $5 \%$ de probabilidade. O coeficiente de determinação foi calculado dividindo a Soma de Quadrado da regressão pela Soma de Quadrado do tratamento. Para realizar as análises estatísticas, empregou-se o programa estatístico SAS (1996).

\section{Resultados e Discussão}

Os valores médios de consumo de ração, de ganho de peso, de conversão alimentar e do coeficiente de variação $(\mathrm{CV})$ para a fase de 1 a 20 dias de idade, de acordo com os níveis de arginina na ração e a relação arginina:lisina digestível, são apresentados na Tabela 5.

Não houve efeito sobre o consumo de ração, todavia, o ganho de peso e a conversão alimentar apresentaram resposta quadrática significativa.

A Figura 1 ilustra os valores de exigências encontrados pelos modelos quadrático e descontínuo para o ganho de peso. Com modelo quadrático, observou-se exigência de 1,27\% de arginina digestível e com o modelo descontínuo, de $1,22 \%$.

A Figura 2 ilustra os valores de exigências obtidos pelos modelos quadrático e descontínuo para conversão alimentar. Pelo modelo quadrático, observou-se exigência de $1,28 \%$ de arginina digestível e com o modelo descontínuo, de $1,23 \%$. Deve-se ressaltar que o valor de exigência de arginina total registrado pelo modelo descontínuo foi de 1,31 e 1,32\%, respectivamente, para ganho de peso e conversão alimentar.

Observa-se que os valores de exigência de arginina digestível para ganho de peso $(1,22 \%)$ e conversão alimentar $(1,23 \%)$, pelo modelo descontínuo, foram ligeiramente semelhantes, correspondendo a uma relação arginina:lisina digestível de $105 \%$ - idêntica à recomendada (105\%) por Baker \& Han (1994) e Rostagno et al. (2000).

Labadan et al. (2001), em experimentos com frangos de corte (machos Ross x fêmeas Avian), encontraram exigências de arginina total para as duas primeiras semanas de vida de 1,24 e $1,28 \%$, respectivamente, para ganho de peso e conversão alimentar, valores inferiores aos de arginina total $(1,31 \%)$, obtidos neste experimento, para ganho de peso e conversão alimentar (1,32\%), adotando o mesmo modelo.

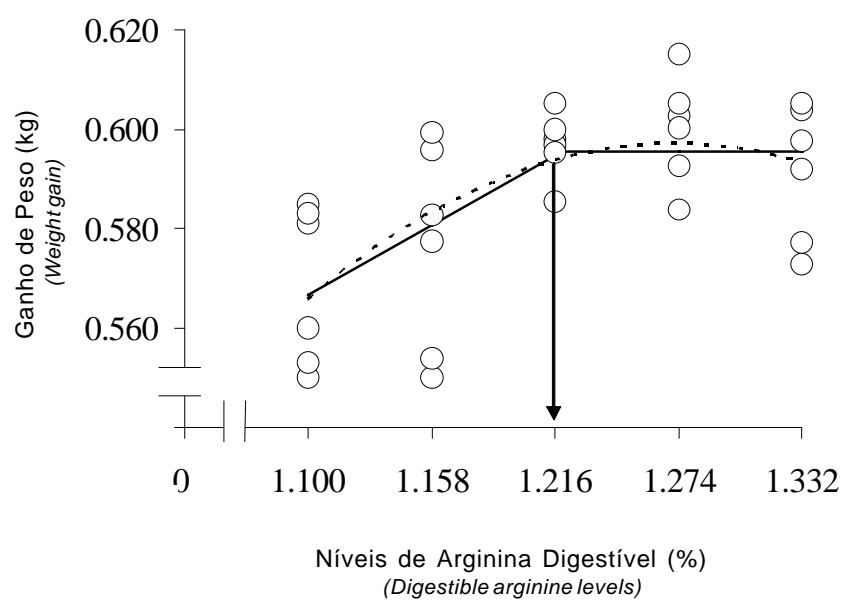

- Representa o valor observado de cada repetição.

( ${ }^{0}$ Represent the observed value of each repetition)

- Modelo Quadrático (Quadratic model ): Exigência (Requirement) $=1,27 \%$

$v=-1,1102+2,6837^{*} X-1,0545^{* *} X^{2} \quad\left(r^{2}: 0,89\right)$

- Modelo descontínuo (Broken Line model) : Exigência (Requirement) $=1,22 \%$

$v=0,5958-0,2414 *(1,2205-X) * i\left(r^{2}: 0,92\right)$

Se $\mathrm{X}<$ exigência $\mathrm{i}=1$ do contrário $=0$

(If $x<$ than the requirement $i=1$ otherwise $=0$ )

Figura 1 - Efeito dos níveis de arginina digestível sobre o ganho de peso de frangos de corte de 1 a 20 dias de idade.

Figure 1 - Effect of arginine level on the weight gain of broilers from 1 to 20 days of age. 
Chamruspollert et al. (2001) registraram exigência de arginina total de $1,26 \%$, para ganho de peso, e de $1,27 \%$, para conversão alimentar, utilizando pintos de corte Ross de 1 a 21 dias de idade, sob temperatura controlada de $25^{\circ} \mathrm{C}$. Porém, a $35^{\circ} \mathrm{C}$, os valores de exigência foram de $1,15 \%$ para ganho de peso e $1,13 \%$ para conversão alimentar. Os valores encontrados a $25^{\circ} \mathrm{C}$ foram mais próximos aos de arginina total estimados neste experimento, empregando o mesmo modelo estatístico. Ressalta-se que a temperatura média neste experimento foi de $23^{\circ} \mathrm{C}$, em ambiente não-controlado.

As médias de ganho de peso, do consumo de ração e de conversão alimentar, para a fase de 24 a 38 dias de idade, são apresentadas na Tabela 6 e as médias de rendimento de carcaça, de peso absoluto do peito, de peso absoluto do filé e de peso absoluto da perna (coxa e sobrecoxa), na Tabela 7.

Não se observou efeito do nível de arginina sobre qualquer característica avaliada, sugerindo que o nível de $1,083 \%$ de arginina digestível $(1,155 \%$ de arginina total), correspondente à relação arginina:lisina digestível de $102 \%$, pode ser suficiente para maximizar o desempenho e a produção de cortes nobres de machos alimentados com dietas contendo 19,9\% de proteína bruta. O desempenho zootécnico com o menor nível de arginina digestível (1,083\%) apresentou o pior resultado de conversão alimentar, e de pesos absolutos do filé e da perna.

Os resultados de desempenho verificados durante esse período estão de acordo com Costa et al. (2001), que não observaram efeito para as características de desempenho em frangos de corte machos (Ross), na fase de 22 a 42 dias de idade, utilizando relação de arginina:lisina variando de 95 a 132,5\% e níveis de lisina digestível de $1,05 \%$.
A relação arginina:lisina digestível (102\%) obtida neste experimento diverge da recomendada por Mack et al. (1999) e Rosatgno et al. (2000), de 112 e $108 \%$, respectivamente. Rostagno et al. (2000) sugerem $1,23 \%$ de arginina total para dietas com $3.150 \mathrm{kcal} / \mathrm{kg}$ de energia metabolizável e $1,17 \%$ de lisina total.

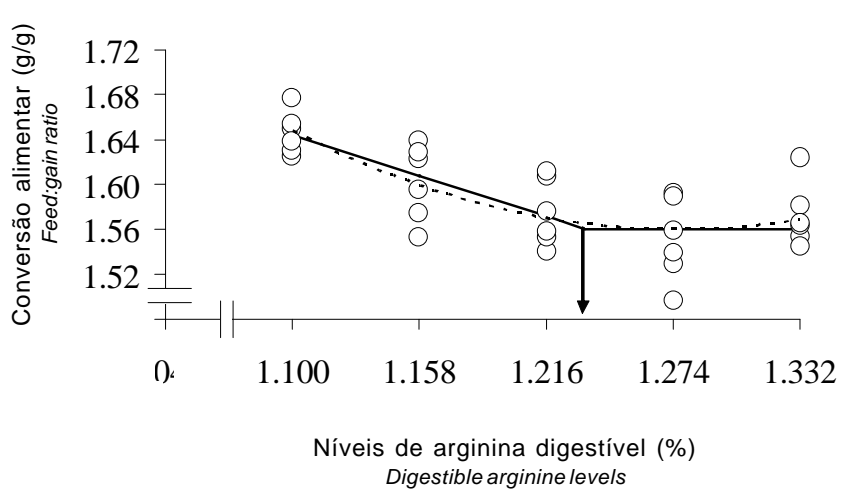

\footnotetext{
- Representa o valor observado de cada repetição.

${ }^{0}$ Represent the observed value of each replicate.

- Modelo quadrático (Quadratic model): Exigência (Requirement) = $1,28 \%$

$v=6,0782-7,063^{* *} X+2,7603^{* *} X^{2} \quad\left(r^{2}: 0,98\right)$

- Modelo descontínuo (Broken line model): Exigência $=1,23 \%$

$v=1.5608+0,6178 *(1,234-X) * i\left(r^{2}: 0,96\right)$

Se $\mathrm{X}<$ exigência $\mathrm{i}=1$ do contrário $=0$

(If $x<$ than the requirement $i=1$ otherwise $=0$ )
}

Figura 2 - Efeito dos níveis de arginina digestível sobre a conversão alimentar em frangos de corte de 1 a 20 dias de idade.

Figure 2 - Effect of arginine level on feed conversion of broilers from 1 to 20 days of age.

Tabela 4 - Níveis nutricionais para as diferentes fases de criação ${ }^{1}$

Table 4 - Nutritional level in the different phases ${ }^{1}$

\begin{tabular}{ccccc}
\hline $\begin{array}{c}\text { Experimento } \\
\text { Experiment } \\
\text { (Idade em dias) } \\
\text { (Age in days) }\end{array}$ & $\begin{array}{c}\text { Proteína bruta calculada } \\
\text { Calculated crude protein } \\
(\%)\end{array}$ & $\begin{array}{c}\text { Lisina dig. } \\
\text { Dig. lysine } \\
(\%)\end{array}$ & $\begin{array}{c}\text { Arginina dig. } \\
\text { Dig. arginine } \\
(\%)\end{array}$ & $\begin{array}{c}\text { Incremento de L-arginina } \\
\text { Arginine increase } \\
(\%)\end{array}$ \\
\hline $1-20$ & 21,9 & 1,16 & $1,100-1,340$ & 0,061 \\
$24-38$ & 19,9 & 1,06 & $1,083-1,296$ & 0,053 \\
$44-56$ & 17,9 & 0,94 & $0,960-1,148$ & 0,047 \\
\hline
\end{tabular}

${ }^{1}$ Cinco níveis de arginina digestível (dig.) com igual incremento foram utilizados em cada fase.

${ }^{1}$ Five equally spaced arginine levels were used in the different phases.

R. Bras. Zootec., v.33, n.6, p.1456-1466, 2004 
Tabela 5 - Médias de consumo de ração, de ganho de peso e de conversão alimentar de pintos de corte de 1 a 20 dias de idade, de acordo com o nível de arginina digestível (Arg. Dig.) da ração

Table 5 - Means of feed intake, weight gain and feed:gain ratio of broiler chicks in the phase 1 to 20 days of age, according to the digestible arginine levels

\begin{tabular}{|c|c|c|c|c|}
\hline $\begin{array}{c}\text { Relação Arg:Lis } \\
\text { Digestible Arg:lys ratio } \\
(\%)\end{array}$ & $\begin{array}{c}\text { Níveis arg. dig. } \\
\text { Digestible arg. levels } \\
(\%)\end{array}$ & $\begin{array}{l}\text { Consumo de ração } \\
\text { Feed intake } \\
(\mathrm{g})\end{array}$ & $\begin{array}{l}\text { Ganho de peso } \\
\text { Weight gain } \\
(\mathrm{g})\end{array}$ & $\begin{array}{l}\text { Conversão alimentar } \\
\text { Feed:gain ratio }\end{array}$ \\
\hline 95 & 1,100 & 936 & 568 & 1,64 \\
\hline 100 & 1,158 & 923 & 576 & 1,60 \\
\hline 105 & 1,216 & 939 & 597 & 1,57 \\
\hline 110 & 1,274 & 931 & 600 & 1,55 \\
\hline 115 & 1,332 & 929 & 592 & 1,57 \\
\hline $\mathrm{CV}(\%)$ & & 2,56 & 2,45 & 1,92 \\
\hline Regressão & & NS & $\mathrm{Q}^{* *}$ & $\mathrm{Q}^{* *}$ \\
\hline Regression & & & & \\
\hline \multicolumn{5}{|c|}{$\begin{array}{l}\mathrm{Q}^{* *} \text { - efeito quadrático }(P<0,01) \\
Q^{*}-\text { Quadratic effect }(P<.01) . \\
\text { NS: F não-significativo a } 5 \% \text { de probabilidade. } \\
\text { NS: F not significant at } 5 \% \text { of probability. }\end{array}$} \\
\hline \multicolumn{5}{|c|}{$\begin{array}{l}\text { Tabela } 6 \text { - Médias de consumo de ração, de ganho de peso e de conversão alimentar de frangos de corte de } 24 \text { a } 38 \\
\text { dias de idade, de acordo com o nível de arginina digestível (Arg. Dig.) da ração } \\
\text { Table } 6 \text { - Means of feed intake, weight gain and feed:gain ratio of broilers in the phase of } 24 \text { to } 38 \text { days of age, according to the } \\
\text { digestible arginine levels }\end{array}$} \\
\hline $\begin{array}{l}\text { Relação Arg:Lis } \\
\text { Digestible Arg:lys ratio } \\
(\%)\end{array}$ & $\begin{array}{l}\text { Níveis arg. dig. } \\
\text { Digestible arg. level } \\
(\%)\end{array}$ & $\begin{array}{l}\text { Consumo de ração } \\
\text { Feed intake } \\
\quad(\mathrm{g})\end{array}$ & $\begin{array}{l}\text { Ganho de peso } \\
\text { Weight gain } \\
\quad(\mathrm{kg})\end{array}$ & $\begin{array}{l}\text { Conversão alimentar } \\
\text { Feed:gain ratio } \\
(\mathrm{g} / \mathrm{g})\end{array}$ \\
\hline 102 & 1,083 & 2,255 & 1,171 & 1,93 \\
\hline 107 & 1,136 & 2,256 & 1,179 & 1,91 \\
\hline 112 & 1,189 & 2,251 & 1,180 & 1,90 \\
\hline 117 & 1,243 & 2,266 & 1,185 & 1,91 \\
\hline 122 & 1,296 & 2,270 & 1,200 & 1,89 \\
\hline $\mathrm{CV}(\%)$ & & 1,80 & 2,34 & 2,02 \\
\hline Regressão & & NS & NS & NS \\
\hline
\end{tabular}

NS: $F$ não-significativo a $5 \%$ de probabilidade.

NS: $F$ not significant at $5 \%$ of probability.

Tabela 7 - Médias de rendimento de carcaça e peso absoluto dos cortes nobres de frangos de corte de 24 a 38 dias de idade de acordo com o nível de arginina digestível (Arg. Dig.) da ração

Table 7 - Means of carcass yield and absolute weight of the different parts of broilers from 24 to 38 days old, according to the digestible arginine (Dig. Arg) levels

\begin{tabular}{|c|c|c|c|c|c|c|}
\hline $\begin{array}{c}\text { Relação } \\
\text { arg:Lis } \\
\text { Digestible } \\
\text { arg:lys ratio } \\
(\%)\end{array}$ & $\begin{array}{l}\text { Nível de } \\
\text { arg dig. } \\
\text { Dig. } \\
\text { arg level } \\
(\%)\end{array}$ & $\begin{array}{c}\text { Peso vivo } \\
\text { das aves } \\
\text { Average } \\
\text { slaughter weight } \\
(\mathrm{kg})\end{array}$ & $\begin{array}{c}\text { Rendimento } \\
\text { de carcaça } \\
\text { Carcass } \\
\text { yield } \\
(\%)\end{array}$ & $\begin{array}{l}\text { Peso absoluto } \\
\text { do peito } \\
\text { Breast } \\
\text { absolute weight } \\
\text { (g) }\end{array}$ & $\begin{array}{c}\text { Peso absoluto } \\
\text { do filé } \\
\text { Breast meat } \\
\text { fillet absolute weight } \\
\text { (g) }\end{array}$ & $\begin{array}{l}\text { Peso absoluto } \\
\text { da perna } \\
\text { Leg quarters } \\
\text { absolute weight } \\
\text { (g) }\end{array}$ \\
\hline 102 & 1,083 & 2,087 & 65,3 & 469 & 330 & 403 \\
\hline 107 & 1,136 & 2,116 & 64,9 & 468 & 344 & 422 \\
\hline 112 & 1,189 & 2,102 & 66,2 & 477 & 347 & 422 \\
\hline 117 & 1,243 & 2,102 & 65,7 & 477 & 347 & 420 \\
\hline 122 & 1,296 & 2,146 & 65,7 & 476 & 348 & 424 \\
\hline $\mathrm{CV}(\%)$ & & 1,65 & 1,72 & 3,88 & 4,69 & 4,05 \\
\hline $\begin{array}{l}\text { Regressão } \\
\text { Regression }\end{array}$ & & & NS & NS & NS & NS \\
\hline
\end{tabular}

NS: $\mathrm{F}$ não-significativo a $5 \%$ de probabilidade.

NS: $F$ not significant at $5 \%$ of probability.

R. Bras. Zootec., v.33, n.6, p.1456-1466, 2004 
A dieta com o menor nível de arginina digestível $(1,083 \%)$ apresentou concentração de arginina total calculada de $1,16 \%$, nível superior ao de arginina total $(1,10 \%)$ recomendado pelo NRC (1994), para a fase de 3 a 6 semanas de idade, em dietas com $3.200 \mathrm{kcal} / \mathrm{kg}$ de energia metabolizável e 1,00\% de lisina total.

Labadan et al. (2001), trabalhando com frangos de corte, encontraram exigência de arginina total para a fase de 3 a 6 semanas de idade, pelo modelo descontínuo, de $0,92 \%$ para ganho de peso, $0,97 \%$ para produção de peito e $0,95 \%$ para conversão alimentar, portanto, inferior ao menor nível de arginina total utilizado neste experimento.

As características de desempenho e peso absoluto dos cortes não diferiram significativamente com a adição crescente de arginina, comprovando que os menores níveis de arginina nesta fase estavam dentro das exigências, o que impossibilitou o cálculo do valor de exigência com base em modelos de regressão.

As médias de ganho de peso, de consumo de ração e de conversão alimentar, para a fase de 44 a 56 dias de idade, são apresentadas na Tabela 8 , enquanto as médias de rendimento de carcaça, de peso absoluto do peito, de peso absoluto do filé e de peso absoluto da perna se encontram na Tabela 9.

Não se observou efeito do nível de arginina sobre qualquer característica avaliada, sugerindo que o nível de $0,960 \%$ de arginina digestível $(1,026 \%$ de arginina total), correspondente à relação arginina:lisina digestível de $102 \%$, pode ser suficiente para maximizar o desempenho e a produção de cortes nobres. A dieta com o maior nível de arginina digestível apresentou o pior resultado para ganho de peso e conversão alimentar, provavelmente em razão do elevado nível de arginina tenha, visto que o excesso de aminoácido proporciona maior gasto de energia para sua biotransformação e eliminação.

A relação arginina:lisina digestível de $102 \%$ registrada contraria a de $109 \%$ sugerida por Rostagno et al. (2000).

A dieta com menor nível de arginina digestível apresentou $1,026 \%$ de arginina total, valor superior ao recomendado pelo NRC (1994), de 1,00\%, para dieta com $3.200 \mathrm{kcal} / \mathrm{kg}$ de energia metabolizável e nível de lisina total de $0,85 \%$.

A ausência de efeitos nas características de desempenho, nas fases de 24 a 38 e 44 a 56 dias de idade, talvez tenha sido resultado do aumento no consumo de ração, uma vez que os experimentos foram conduzidos sob baixas temperaturas. De acordo com o Manual da Avian Farm (1998), o consumo de ração para frangos machos na fase de 24 a 38 dias de idade é de $2,099 \mathrm{~kg}$, portanto, inferior ao consumo de ração médio de 2,260 kg observado neste experimento. Em dias frios, o consumo de ração aumenta, ocasionando maior consumo de arginina (em gramas), o que pode resultar em níveis de exigência (\% da dieta) inferiores.

Tabela 8 - Médias de consumo de ração, ganho de peso e conversão alimentar de frangos de corte no período de 44 a 56 dias de idade, de acordo com o nível de arginina digestível da ração

Table 8 - Means of feed intake, weight gain and feed:gain ratio of broilers from 44 to 56 days of age, according to the digestible arginine levels

\begin{tabular}{ccccc}
\hline $\begin{array}{c}\text { Relação Arg:Lis } \\
\begin{array}{c}\text { Digestible Arg:lys ratio } \\
(\%)\end{array}\end{array}$ & $\begin{array}{c}\text { Níveis de Arg } \\
\text { Digestible Arg. level } \\
(\%)\end{array}$ & $\begin{array}{c}\text { Consumo de ração } \\
\text { Feed intake } \\
(\mathrm{kg})\end{array}$ & $\begin{array}{c}\text { Ganhode peso } \\
\text { Weight gain } \\
(\mathrm{kg})\end{array}$ & $\begin{array}{c}\text { Conversãoalimentar } \\
\text { Feed:gain ratio } \\
(\mathrm{kg} / \mathrm{kg})\end{array}$ \\
\hline 102 & 0,960 & 2,632 & 1,076 & 2,45 \\
107 & 1,007 & 2,650 & 1,077 & 2,46 \\
112 & 1,054 & 2,653 & 1,078 & 2,46 \\
117 & 1,101 & 2,639 & 1,080 & 2,45 \\
122 & 1,148 & 2,649 & 1,052 & 2,51 \\
\hline CV $(\%)$ & & 3,28 & 3,78 & $\mathrm{NS}$ \\
\hline Regressão & $\mathrm{NS}$ & $\mathrm{NS}$ & \\
Regression & & & & \\
\hline
\end{tabular}

NS: $F$ não-significativo a $5 \%$ de probabilidade.

NS: $F$ not significant at $5 \%$ of probability.

R. Bras. Zootec., v.33, n.6, p.1456-1466, 2004 
Tabela 9 - Médias de rendimento de carcaça e peso absoluto dos cortes nobres de frangos de corte no período de 44 a 56 dias de idade, de acordo com o nível de arginina digestível (Arg. Dig.) da ração

Table 9 - Means of carcass yield and absolute weight of the different parts in broilers from 44 to 56 days old, according to the digestible arginine (Dig. Arg.) levels

\begin{tabular}{|c|c|c|c|c|c|c|}
\hline $\begin{array}{c}\text { Relação } \\
\text { arg:lis } \\
\text { Digestible } \\
\text { arg:lys ratio } \\
(\%)\end{array}$ & $\begin{array}{l}\text { Nível de } \\
\text { arg. dig. } \\
\text { Dig. } \\
\text { Arg level } \\
\quad(\%)\end{array}$ & $\begin{array}{c}\text { Peso vivo } \\
\text { das aves } \\
\text { Average } \\
\text { slaughter weight } \\
(\mathrm{kg})\end{array}$ & $\begin{array}{c}\text { Rendimento } \\
\text { de carcaça } \\
\text { Carcass } \\
\text { yield } \\
(\%)\end{array}$ & $\begin{array}{l}\text { Peso absoluto } \\
\text { do peito } \\
\text { Breast } \\
\text { absolute weight } \\
\text { (g) }\end{array}$ & $\begin{array}{c}\text { Peso absoluto } \\
\text { do filé } \\
\text { Breast meat } \\
\text { fillet absolute weight } \\
\text { (g) }\end{array}$ & $\begin{array}{l}\text { Peso absoluto } \\
\text { da perna } \\
\text { Leg quarter } \\
\text { absolute weight } \\
\text { (g) }\end{array}$ \\
\hline 102 & 0,960 & 3,748 & 68,0 & 870 & 657 & 789 \\
\hline 107 & 1,007 & 3,745 & 68,7 & 873 & 667 & 802 \\
\hline 112 & 1,054 & 3,743 & 68,3 & 877 & 665 & 810 \\
\hline 117 & 1,101 & 3,739 & 68,3 & 875 & 667 & 798 \\
\hline 122 & 1,148 & 3713 & 68,9 & 872 & 654 & 802 \\
\hline $\mathrm{CV}(\%)$ & & 1,55 & 2,50 & 3,61 & 5,34 & 5,92 \\
\hline $\begin{array}{l}\text { Regressão } \\
\text { (Regression) }\end{array}$ & & NS & NS & NS & NS & NS \\
\hline
\end{tabular}

NS: $\mathrm{F}$ não-significativo a $5 \%$ de probabilidade.

NS: F not significant at $5 \%$ of probability.

\section{Conclusões}

Nas condições do presente experimento, as exigências de arginina digestível nos períodos de 1 a 20 , 24 a 38 e 44 a 56 dias foram de 1,22 (1,31\% Arg. total), $1,083(1,155 \%$ Arg. total) e $0,960 \%(1,026 \%$ Arg. total), respectivamente, o que corresponde a uma relação arginina:lisina digestível de 105, 102 e $102 \%$.

\section{Literatura Citada}

AVIAN FARMS. Broiler manual. In: http://www.avianfarms.com. Avian Farms International, Inc., 1998, 34p.

BAKER, D.H.; HAN, Y. Ideal amino acid profilé for chicks during the first three weeks posthatching. Poultry Science, v.73, p.1441-1447, 1994.

BURTON, E.M.; WALDROUP, P. Arginine and lysine needs of young broiler chicks. Nutrition International, v.19, p.607-614, 1997.

CHAMRUSPOLLERT, M. Interrelationships between dietary arginine, methionine, and environmental temperature affect growth and creatine biosynthesis in young broiler chicks. Athens, Georgia: University of Georgia, 2001. 236p. (PhD Thesis) - University of Georgia, 2001.

COSTA, F.G.P.; ROSTAGNO, H.S.; TOLEDO, R.S. et al. Efeito da relação arginina:lisina sobre o desempenho e qualidade da carcaça de frangos de corte de 3 a 6 semanas de idade, em condições de alta temperatura. Revista Brasileira de Zootecnia, v.30, n.6, p.2021-2028, 2001. (suplemento)

EMMERT, J.L.; BAKER, D.H. Use of the ideal protein concept for precision formulation of amino acid levels in broiler diets. Journal of Applied Poultry Research, v.6, p.462-470, 1997.
LABADAN Jr., M.C.; HSU, K.N.; AUSTIC, R.E. Lysine and arginine requirements of broiler chickens at two to three weeks intervals to eight weeks of age. Poultry Science, v.80, p.599-606, 2001.

MACK, S.; BERCOVICI, D.; DE GROOTE, G. et al. Ideal amino acid profilé and dietary lysine specification for broiler chickens of 20 to 40 days of age. British Poultry Science, v.40, p.257-265, 1999 .

Mc LEOD, M. Effects of amino acid balance and energy: protein ratio on energy and nitrogen metabolism in male broiler chicken. British Poultry Science, v. 38, p. 405-411, 1997.

MONGIN, P. Recent advances in dietary anion-cation valance: application in poultry. Proceeding Nutrition Society, v.40, p.285-294, 1981.

NATIONAL RESEARCH COUNCIL - NRC. Nutrient requirement of poultry. 9.ed. Washington, D.C.: National Academy, 1994. 155p.

ROSTAGNO, H.S.; ALBINO, L.F.T.; DONZELE, J.L. et al. Tabelas brasileiras para aves e suínos. Composição de alimentos e exigências nutricionais. Viçosa, MG: Universidade Federal de Viçosa, 2000. 141p.

PARSONS, C. M.; BAKER, D. H. The concept and use of ideal proteins in feeding of nonruminants. In: SIMPÓSIO INTERNACIONAL DE PRODUÇÃO DE NÃORUMINANTES, 1994, MARINGÁ. Anais... Maringá: Sociedade Brasileira de Zootecnia, 1994. p.119-128.

SCHUTTE, J.B.; SMINK, W.; PACK M. Requirement of young broiler chicks for glycine + serine. Arch Geftugelk, v.61, n.1, p.43-47, 1997.

STATISTICAL ANALYSES SYSTEM - SAS. SAS guide statistics. Version 6. 12.ed. Cary: 1996.

Recebido em: 19/02/03 Aceito em: 04/02/04 